\title{
PROBABILISTIC ANALYSIS OF TUNNEL LINERS
}

\author{
A. Fraile, M.S. Gomez Lera and E. Alarcon \\ Department of Structural Mechanics and Industrial Constructions, Technical \\ University of Madrid, Madrid, Spain
}

\begin{abstract}
The use of probabilistic methods to analyse reliabiliy of structures is being applied to a variety of engineering problems due to the possibility of establishing the failure probability on rational grounds. In this paper we present the application of classical reliability theory to analyse the safety of underground tunnels.
\end{abstract}

\section{General}

The continuous development of transportation networks with stringent geometric conditions has induced an increasing pace of tunnel construction. Generally the techniques used to build them are based on a careful control of the structural response of the lining and this implies the use of sophisticated numerical techniques of analysis to predict and interpret the experimental results. In particular it would be interesting to have a measure of the liner reliability in relation with the different conditions that could be expected to limit the tunnel performance.

In that sense the use of the Limit State philosophy, widely admitted in other areas of structural analysis, seems to be very promising. The same can be said in relation with the so-called Level II methods of structural reliability that allows the implementation of a general procedure as well as the possibility of calibration of Codes of Practice based on the factored load and resistance properties.

In this paper we are going to show the way in which we have tried to establish a procedure to quantify the reliability of road tunnel liners.

The plan of the paper is as follows: first of all we shall describe some details of the physical process, then a series of Limit States will be defined. After that, a simple mathematical model will be defined according to the very well known New Austrian Tunneling Method (NATM) procedure. After summarizing some results obtained with Level II methods, more general models will be presented that can be applied to a variety of situations including classical Terzaghi approach or the Panet procedure to simulate 3D conditions using 2D procedures.

\section{The physical model}

The problem that arises in tunnel piercing can be explained using figure 1. In it four zones have been established in a sequence through which all sections of the tunnel have to pass.

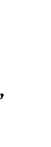




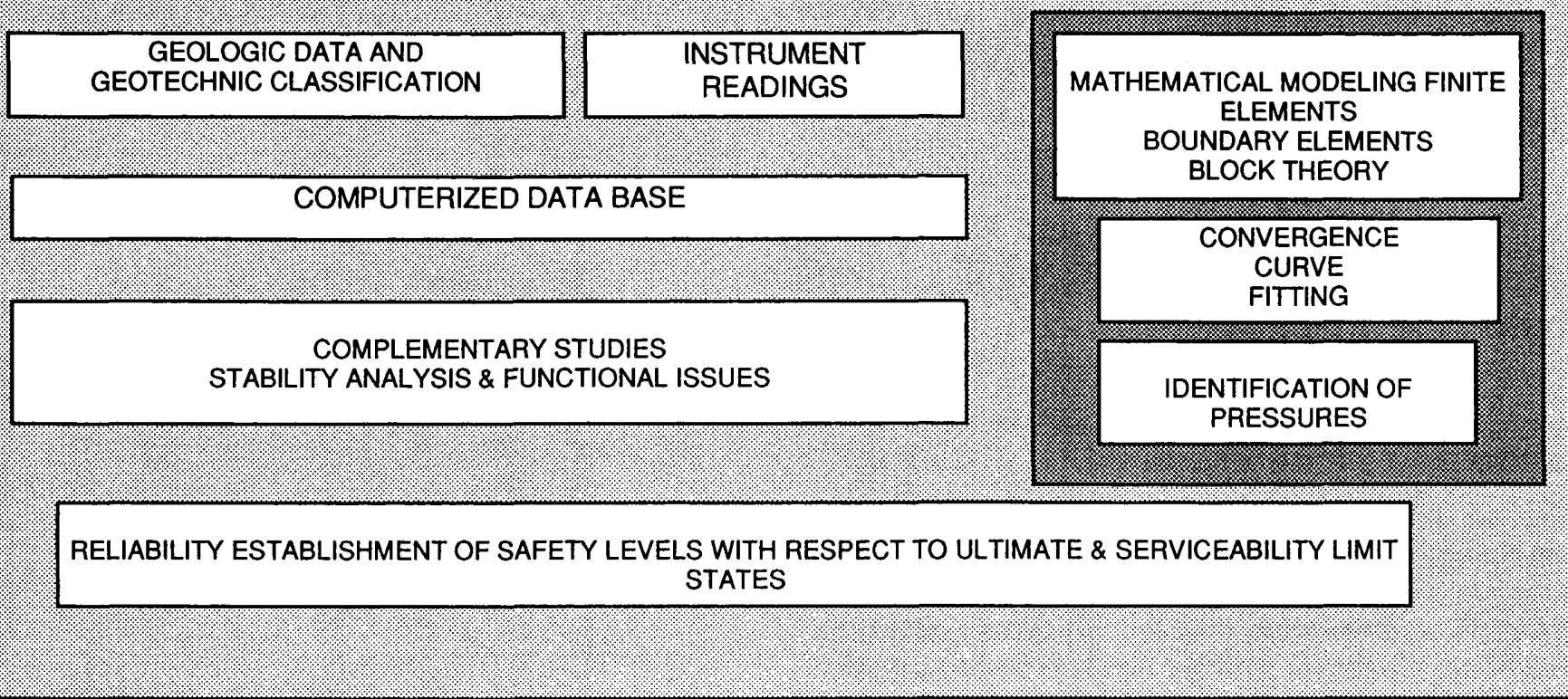

Figure 2

\section{$3 \quad$ Limit States}

The limit states are related, as usual, to conditions that have to be fulfilled in order to mantain the serviceability or to guarantee the resistance of the tunnel. We propose to select as a first limit state a value related to the convergences.

On the one hand convergences measure the degree of stabilization of the soil-liner system but on the other they also reflect the accuracy of the geometric dimensions of the structure. In case of symmetric deeply embedded structures the convergence is twice the radial component of the displacements.

The admissible value is usually taken as a proportion $\alpha, \mathrm{R}$ of the liner radius, so the first condition is

$$
f_{1}\left(K_{0} ; \gamma_{s} ; H ; \text { etc }\right) \leq \alpha R
$$

where $f_{1}\left(K_{0}, K_{s}, H\right.$, etc) is a function of the at rest coefficient $K_{0}$, soil density $\gamma_{\mathrm{s}}$, depth of embedment $H$, and other parameter influencing displacements. If conditions are non symmetric the limit-state could be based on the absolute maximum of the displacements or on a weighted mean value that can take into consideration the different importance of displacements in relation with the use of space (i.e.: a ventilation duct, or a traffic space or the part outside the circulation area, etc).

The second and third limit states are related to the liner resistance and soil resistance respectively. The liner resistance can be expressed in terms of hoop stresses for the case of symmetric scenarios as a function

$$
f_{2}\left(t, R, f_{c k}^{\prime} \text { etc }\right) \leq \alpha_{2} f_{c k}^{\prime}
$$

where $t, R, f_{c k}^{\prime}$, etc are respectively the liner thickness, liner radius, characteristic value of concrete strength, and any other parameter influencing the resistance.

In less simple cases it would be better to work with actions effects and to establish the admissibility on the basis of an interaction diagram of bending moments, and axial and shear forces.
The soil resistance is another factor to control because the key idea in the New Austrian Tunneling Method (N.A.T.M.) $(3,4)$ it just to create a mixed structure in which the liner supplies radial confinement to the soil in the degree neccesary to obtain a ductile behavior of the rock mass. In that way a soil arch or plastified zone is created around the tunnel. This arching effect is fundamental to obtain the stability and the economy, so the third limit state is related to the soil resistance. A way to control the soil arch in a symmetric situation is to compare the radius of the plastified zone with the liner radius, i.e.

$$
f_{3}\left(K_{0}, \gamma_{s}, H, t, R, \varphi, c, \text { etc }\right) \leq \alpha_{3} R
$$

where the parameters are those of the previous states plus some others like the internal soil friction $\varphi$, cohesion $c$, etc.

In more complicated cases the plastified zone is not concentric with the liner and then it is better to establish a maximum distance or a weighted mean distance to the liner as a criterium.

Other limit states can be envisaged similary depending on the use of the tunnel, the soil conditions, the embedment depth, etc. For instance in shallow depths it is possible that the formation of a key block due to the rock fissuration could be more critical because the confinement pressure could be not high enough to induce ductile behavior. In those cases a different behavioral model would be used as well as a different criterium. In this paper only the above mentioned criterium will be used in order to clarify the application of the reliability philosophy.

\section{Mathematical model}

The classical interpretation of the N.A.T.M. can be explained using figure 3 that can be compared with figure 1 .

The idea is to plot for a symmetric situation the pressures that should be applied to the boundary of a circular hole (figure 3.a) to obtain a fixed radial displacement $\delta$. The curve $A B$ (figure 3.b) shows after an elastic part AA' a curved branch $A^{\prime} B$, reflecting the plastic behaviour of the continuous media. 


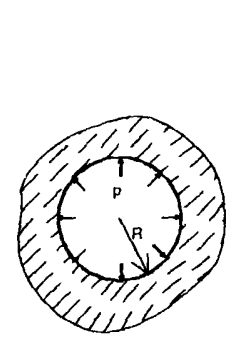

(a)

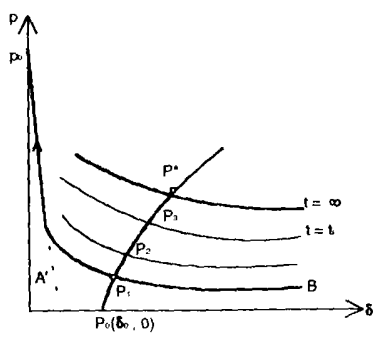

(b)

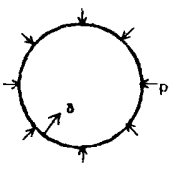

(c)
Figure 3

Similarly it is possible to plot the same relation for a ring representing the liner (figure 3.c). in this case the curve is $P_{0}$ $\mathrm{P}^{*}$ and starts at a point $\left(\delta_{0}, 0\right)$ because before the liner is built (zones I, II and III a of figure 1) the soil has contracted. The equilibrium is reached at point $P_{1}$ except if the soil is viscous in which case a family of $\mathrm{AB}$ curves will develop for different time intervals $t_{i}$. In a viscoplastic soil the final curve will be reached for $t=\infty$ where all the plastic deformations are developed Point $\mathrm{P}^{*}$ will be then the design point or checkpoint because there all the three above mentioned limit states are in the worst conditions.

P. Fritz (ref 5) using a Mohr Coulomb criterium has developed the formula to quantify the soil model. If a linear behaviour of the liner is assumed it is possible to compose Table I

\begin{tabular}{|c|c|}
\hline SOIL & LINER \\
\hline $\begin{array}{l}\frac{\rho}{R}=\left[\left(\sigma_{p}+\frac{\sigma_{d}}{m-1}\right) \frac{1}{\frac{\sigma_{d}}{m-1}+p_{i}}\right]^{1 / m-1} \\
m=\frac{1+\operatorname{sen} \varphi}{1-\operatorname{sen} \varphi} \quad \sigma_{d}=\frac{2 c \cos \varphi}{1-\operatorname{sen} \varphi} \\
\sigma_{\rho}=\frac{2 p_{0}-\sigma_{s}}{1+m} \\
\delta_{i}=R \frac{1+v_{s}}{E_{s}}\left[k_{2}\left(\frac{\rho}{R}\right)^{m+1}+k_{1}\left(\frac{R}{\rho}\right)^{m-1}+k_{3}\right. \\
k_{1}=\left(\sigma_{p}+\frac{\sigma_{d}}{m-1}\right)\left[\left(1-v_{s}\right) \frac{1+m^{2}}{2 m}-v_{s}\right] \\
k_{2}=\left(1-v_{s}\right) \frac{1+m}{2 m}\left[\sigma_{d}+(m-1) \sigma_{\rho}\right] \\
k_{3}=p_{0}-\sigma_{p}-k_{1}-k_{2}\end{array}$ & $\delta_{1}-\delta_{0}=\frac{p_{\mathrm{i}} R^{2}}{E_{1} t}$ \\
\hline
\end{tabular}

\section{Table I}

where symbols have been used the following

$$
\begin{array}{ll}
\rho: & \text { radius of plastified zone } \\
\mathrm{R}: & \text { liner radius }
\end{array}
$$

\begin{tabular}{|c|c|}
\hline$\sigma_{\mathrm{p}}:$ & $\begin{array}{l}\text { radial pressure } p \text { at which plastification } \\
\text { starts }\end{array}$ \\
\hline $\mathrm{m}, \sigma_{\mathrm{d}}$ & $\begin{array}{l}\text { parameters reflecting soil properties } \\
\text { according to Mohr-Coulomb criterium }\end{array}$ \\
\hline $\mathrm{p}_{\mathrm{i}}:$ & internal pressure \\
\hline$\varphi:$ & internal friction angle \\
\hline c: & soil cohesion \\
\hline $\mathrm{p}_{0}:$ & initial soil stress (assumed isotropic) \\
\hline$\delta_{\mathrm{i}}:$ & $\begin{array}{l}\text { radial displacement corresponding to } \\
\mathrm{p}_{\mathrm{i}}\end{array}$ \\
\hline$v_{s} E_{s}:$ & $\begin{array}{l}\text { Poisson coefficient and Young Modulus } \\
\text { of soil }\end{array}$ \\
\hline$\varepsilon^{\prime}:$ & liner hoop deformation \\
\hline$\delta^{1}:$ & liner radial displacement \\
\hline$\delta_{0}:$ & $\begin{array}{l}\text { initial soil displacement before liner is } \\
\text { introduced }\end{array}$ \\
\hline $\mathrm{t}:$ & liner thickness \\
\hline $\mathrm{E}_{1}:$ & liner Young modulus \\
\hline$\sigma_{1 \mathrm{lim}}:$ & liner limit stress \\
\hline
\end{tabular}

Generally it is more realistic for reinforced concrete liners to use a combination of the material laws, as those presented in figure 4 and to limit not the stresses in the liner but the concrete deformation because the ultimate state will be concrete crushing (for instance $\varepsilon_{\mathfrak{u}}=0.003$ )
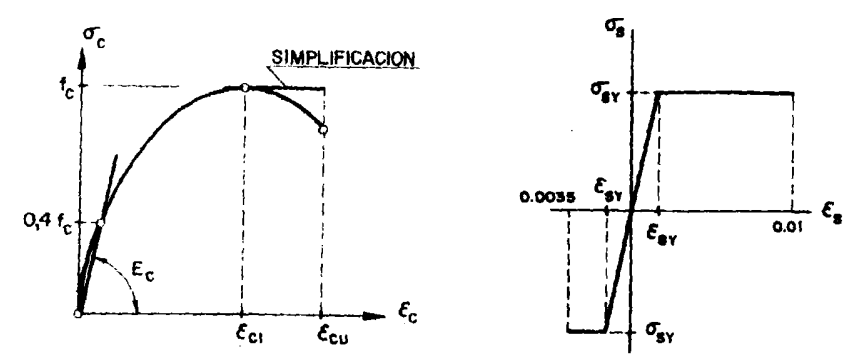

Figure 4

In figure 5 we show the diagram for a particular situation in which the liner has been modeled taking into account the nonlinear concrete behaviour law. (Ref 10)

\section{Reliability level II methods}

As it is well known (ref 6) in addition to limit states it is necessary to choose the basic variables which statistic properties are defined through their mean values and covariances. In the examples we have been treating, 6 variables have been chosen related to the soil $\left(E_{s}, v_{s}, \gamma_{s}, c, \varphi\right.$ and $H)$ and other 6 for the liner $\left(\delta_{0}, f_{c k}^{\prime} t, R, \omega_{s}, \omega_{c}\right)$ where the meaning of each symbol has been defined in previous paragraphs, except $\omega_{3}$ and $\omega_{t}$ that are the ratios of steel reinforcement used as bars or solid profiles respectively.

Using the Hasofer and Lind definition (ref 7) the reliability index for every limit state is related to the minimum distance of the origin to the failure surface when the variables are standardized and make independent after the adequate transformations. 
BEHAVOR FOR MEAN VALUES

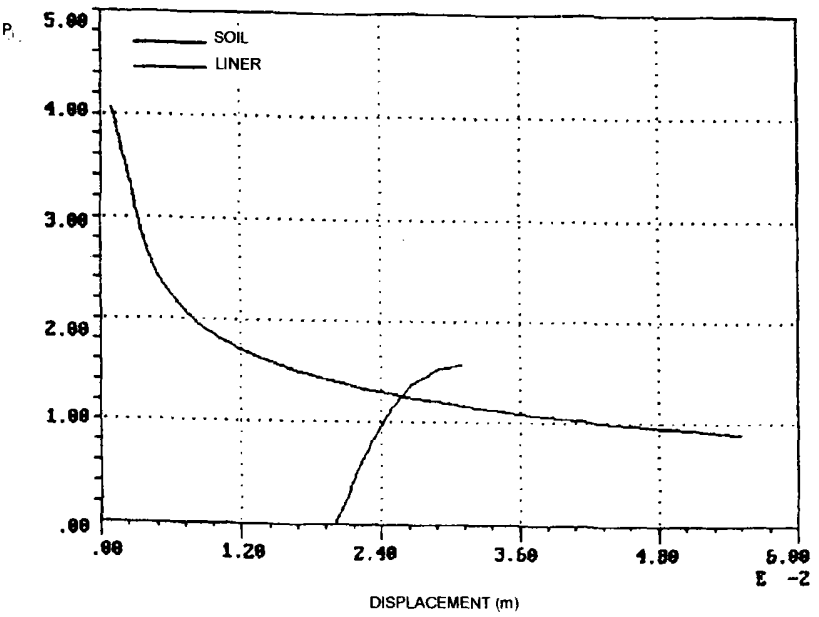

Figure 5

On the other hand, the coordinates of the point at the surface (design point) $\left(\beta \alpha_{1} \beta \alpha_{2} \ldots \ldots \beta \alpha_{N}\right)$ are used to obtain the sensitivities related to the different variables as well as to define weighting factors affecting to values of the stochastic variables.

To obtain the design point we have used the typical Racwitz approach but also a surface response method (ref 11) based on the point estimation (Rosenblueth, (8)).

In this method for functions of $n$ variables it is necessary to obtain estimations at $2^{\mathrm{n}}$ points defined as combinations of the mean plus or minus the standard derivation of every variable. Using the results of those estimates a surface can be adjusted (the simplest case being an hyperplane) and $\beta$ and $\alpha_{i}$ computed to obtain the desired results.

In this case it is very easy to show that if the plane representing the failure plane is expressed as

$$
w=a_{0}+\sum_{1}^{N} a_{j} z_{j}
$$

where $\mathrm{z}_{j}$ are the typified variables (which values are \pm 1 ) then

$$
\begin{aligned}
& a_{0}=\frac{\sum_{1}^{N} w_{i}}{N} \\
& a_{j}=\frac{\sum_{1}^{N} w_{i} z_{j}^{i}}{N}
\end{aligned}
$$

where $\mathrm{N}$ is the number of point estimations.

Then the reliability index, the director cosines $\alpha_{k}$ and the design point $z_{k}{ }^{*}$ are given by

$$
\begin{aligned}
& \beta=\frac{a_{0}}{\sqrt{\sum_{j} a_{j}^{2}}} \\
& \alpha_{k}=\frac{a_{k}}{\sqrt{\sum_{j} a_{j}^{2}}}
\end{aligned}
$$

$$
z_{k}^{*}=\sum_{j}^{a_{k} a_{o}}
$$

Detailed values for mean values and covariance matrices of basic variables can be found in ref 9, related to a road-tunnel in different soil conditions. As an example of the results figure 6 shows.
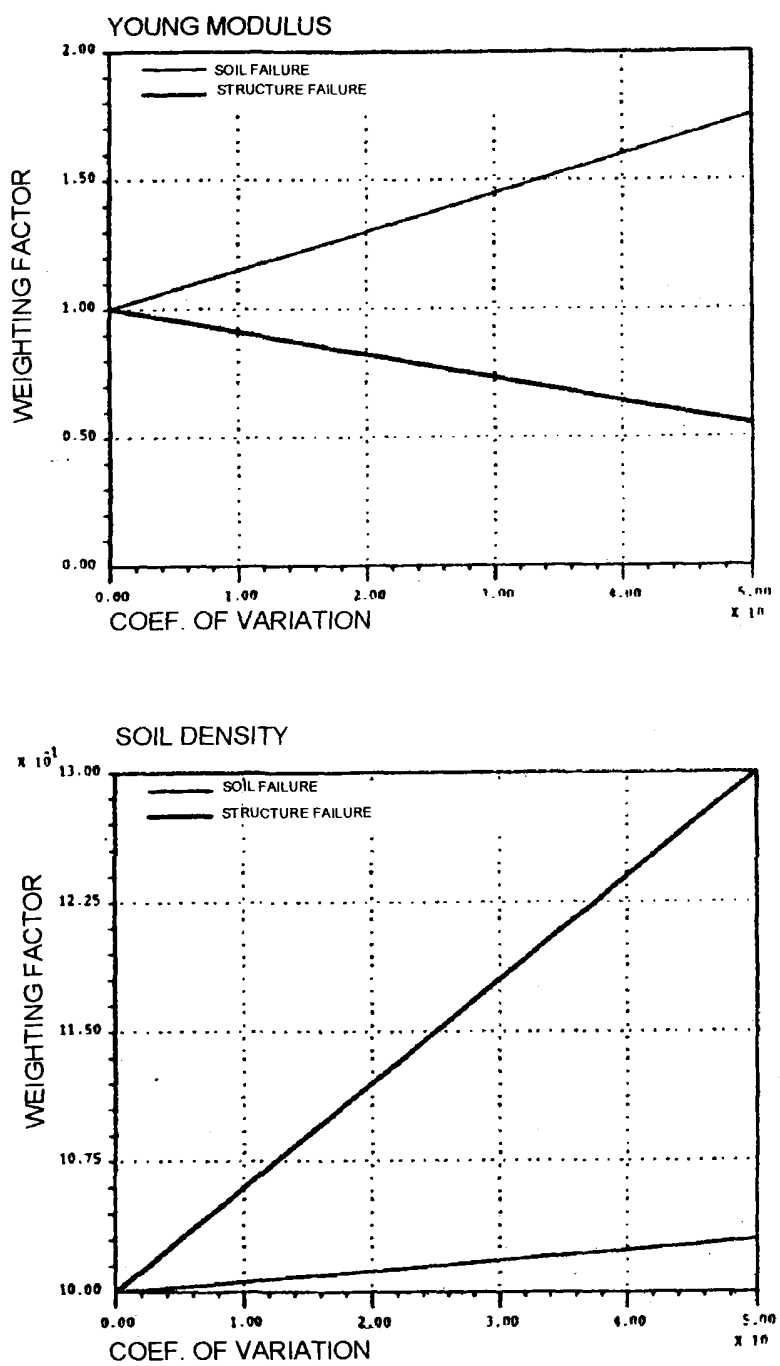

Figure 6

In the probabilistic finite element method one of the procedures to obtain the sensitivity is the development in a Taylor series round the point under consideration by solving sequencially (reference) the systems

$$
\begin{gathered}
K^{0} u^{0}=f^{0} \\
\left.K^{0} \frac{\partial u}{\partial x}\right|^{0}=\left.\frac{\partial f}{\partial x}\right|^{0}-\left.\frac{\partial k}{\partial x}\right|^{0} u^{0}
\end{gathered}
$$

where $\mathrm{K}$ is the stiffness matrix of the system, $f$ the load vector and $u$ the displacement vector, $x$ is the vector of basic stochastic variables and superindex o means that all values are particularized for the basic variable set corresponding to the design point.

In this way it is possible to connect the reliability modulus with a general representation of the problem. 
For instance we have used the previous approach with a Terzaghi method in which, the liner is represented by monodimensional members and the passive pressures by elastic springs (figure 7) while some active pressures are directly applied using some empirical rules (figure 8). This system is well suited for shallow tunnels or arcas near portals

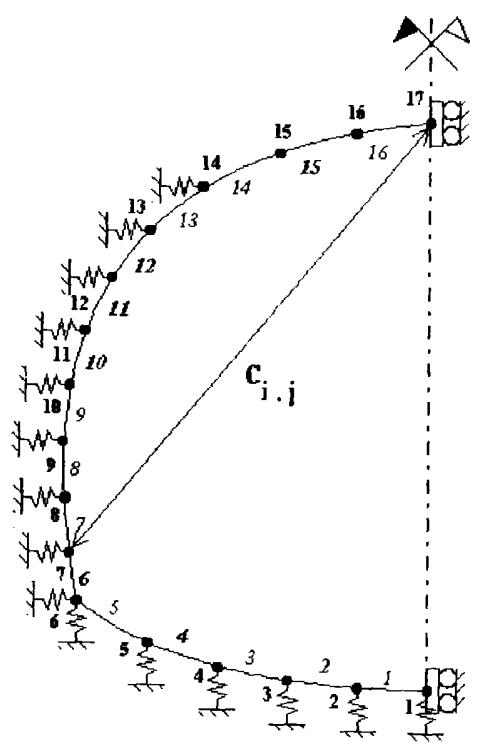

Figure 7

\section{NODAL DISPLACEMENTS}

\begin{tabular}{|c|c|c|c|}
\hline NODE & DISPL. $\mathrm{X}$ & DISPL. Y & ROTAT. Z \\
\hline 1 & 0 & -0.03 & 0 \\
\hline 2 & -0.0002059 & -0.0298239 & 0.0002515 \\
\hline 3 & -0.0003296 & -0.0293388 & 0.0004534 \\
\hline 4 & -0.0003213 & -0.0286435 & 0.0005919 \\
\hline 5 & -0.0001574 & -0.0278221 & 0.0007247 \\
\hline 6 & 0.0002347 & -0.0268497 & 0.0010117 \\
\hline 7 & 0.0011195 & -0.0255626 & 0.0015959 \\
\hline 8 & 0.0028333 & -0.0239318 & 0.001977 \\
\hline 9 & 0.0024892 & -0.0235306 & 0.001977 \\
\hline 10 & 0.004561 & -0.0219528 & 0.0014093 \\
\hline 11 & 0.0059476 & -0.0212753 & 0.0005173 \\
\hline 12 & 0.0060363 & -0.02111 & -0.0005802 \\
\hline 13 & 0.0049981 & -0.0209927 & -0.0013695 \\
\hline 14 & 0.0031523 & -0.0207702 & -0.0017773 \\
\hline 15 & 0.0019959 & -0.0174825 & -0.0022707 \\
\hline 16 & 0.0008091 & -0.0129022 & -0.002992 \\
\hline 17 & -0.0002168 & -0.0074596 & -0.0033018 \\
\hline 18 & -0.0003004 & -0.0027106 & -0.002816 \\
\hline 19 & -0.0002074 & -0.0006508 & -0.0017927 \\
\hline 20 & -0.0001054 & 0.0003652 & -0.0007395 \\
\hline 21 & 0 & 0.0006382 & 0 \\
\hline
\end{tabular}

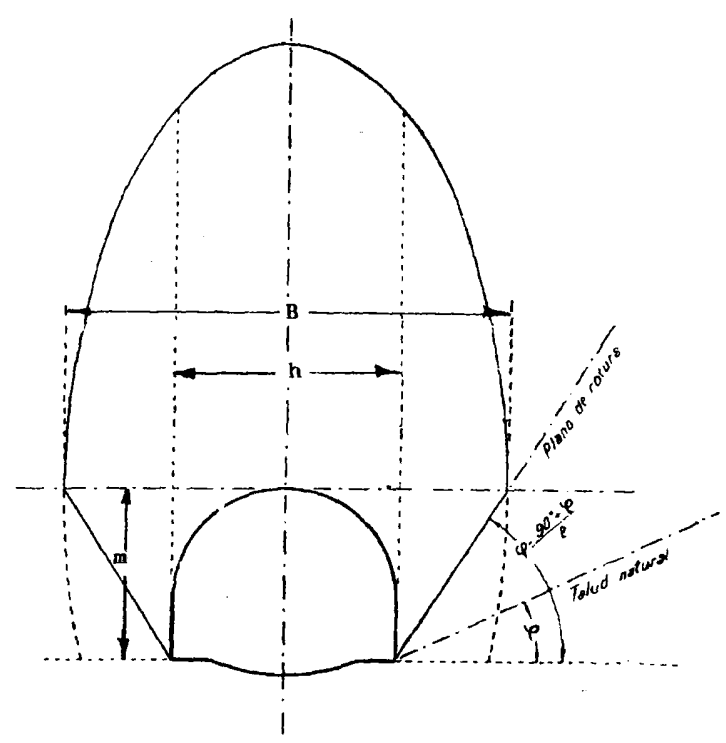

Figure 8

The next tables show the results obtained in an example using the previous definition. In it, was calculated the reliability index of the tunnel using as a failure surface the points where the vertical displacement of the liner crown was $3 \mathrm{~cm}$. The stochastics variables used were the stiffness of the springs. In those tables, the point over the failure surface, the sensitivities coefficients of the springs and the reliability index are shown as well as the weighting factors of the stochastics variables.

\section{FAILURE SURFACE}

\begin{tabular}{|l|r|}
\hline \multicolumn{2}{|l|}{ Sensitivity } \\
\hline Alfa1 & 0.027 \\
\hline Alfa2 & 0.010 \\
\hline Alfa3 & 0.765 \\
\hline Alfa4 & 0.030 \\
\hline Alfa5 & 0.010 \\
\hline Alfa6 & 0.010 \\
\hline Alfa7 & 0.040 \\
\hline Alfa8 & -0.035 \\
\hline Alfa9 & 0.609 \\
\hline Alfa10 & 0.111 \\
\hline Alfa11 & 0.129 \\
\hline Alfa12 & 0.095 \\
\hline Alfa13 & 0.022 \\
\hline Alfa14 & -0.013 \\
\hline Alfa15 & -0.001 \\
\hline Alfa16 & 0.000 \\
\hline & \\
\hline Beta $=$ & 3.3453 \\
\hline Pf(\%)= & 0.0411 \\
\hline
\end{tabular}

\section{WEIGHTING FACTORS}

\begin{tabular}{|r|r|}
\hline Variable & phi \\
\hline 1 & 0.977 \\
\hline 2 & 0.992 \\
\hline 3 & 0.360 \\
\hline 4 & 0.975 \\
\hline 5 & 0.991 \\
\hline 6 & 0.992 \\
\hline 7 & 0.966 \\
\hline 8 & 1.029 \\
\hline 9 & 0.490 \\
\hline 10 & 0.907 \\
\hline 11 & 0.892 \\
\hline 12 & 0.921 \\
\hline 13 & 0.982 \\
\hline 14 & 1.011 \\
\hline 15 & 1.001 \\
\hline 16 & 1.009 \\
\hline
\end{tabular}

Table II 
It is also possible to model a general shape by a 2-D finite element method by using the Panet approach as described by Leca and Clough (ref. 14), i.e.: representing the excavation by a softening ground of the central part of the mesh and the application of an initial stress state as indicated in figure 9.
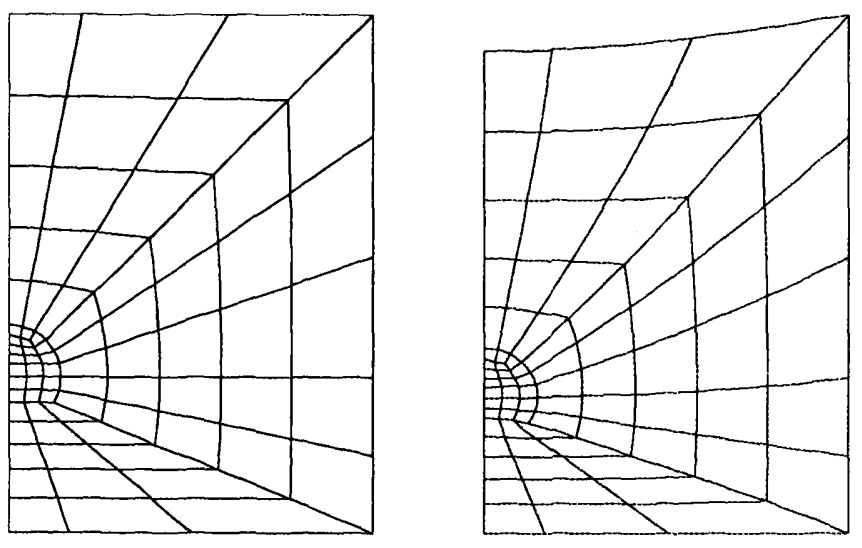

Figure 9

\section{Conclusions}

In the paper we have tried to show how different classical methods of structural reliability can be applied to the assesment of the safety of tunnel liners. Although more work is necessary it is hoped that this line of thought will improve the current measures of safety. In addition it is clear that the procedure can be used as an identification tool for back analysis fixing as limit state the variables to be adjusted.

\section{References}

[1] M. Panet: Calcul des tunnels par le méthode convergence-confinement presses de Ponts et chaussees. 1995

[2] Z.T. Bieniaski: Rock Mechanics Desing in Mining and Tunnelling. Balkema 1983
[3] Rabcewicz: The New Austrian Tunnelling Method. Water Power, Nov, Dec 1964 and January 1965

[4] Rabcewicz: Principles of Dimensioning the supporting system for the NATM. Water Power March 1973

[5] Fritz: An analytical solution for axisymmetric tunnel problems in Elasto-Viscoplastic media. Int. Jour. Num and analyt. Meth in Geomechanics. Vol 81980

[6] Madsen, S. Krenk, N.C. Lind: Methods of structural safety. Prentice 1986

[7] Hasofer, N.C. Lind: Exact and invariant second moment code format. Jour. Eng. Mech. Div. ASCE Vol 100 1974

[8] Rosenblueth: Two-point estimates in probability App. Math. Modell. Vol. 51981

[9] Gómez Lera; E. Alarcón: Introduction to structural reliability theory and some of its applications (in spanish). Repport 408. Instituto de Ciencia de la Construcción Eduardo Torroja. 1992

[10] E. Laso, M.S. Gómez Lera, E. Alarcón: A level II reliability approach to tunnel support design. App. Math. Modell. Vol. 19, 1995

[11] E.P. Box, N.R. Draper: Empirical Model-Building and response surfaces. App. Math. Modell. J. Wiley 1987

[12] Kleiber, T.D. Hien: The stochastic finite element method. Wiley 1992

[13] Liu, T. Belytschko: Computational Mechanics of Probabilistic and reliability analysis. Elmpress Intern. 1989

[14] Leca, W. Clough: Preliminary design for NATM Tunnel Support in Soil. ASCE Jour. Geotech. Eng. Vol. 118 1992

[15] E. Laso: Application of level II structural reliability methods to tunnel liners. (In Spanish). Thechnical University of Madrid (UPM), 1991 